\title{
Acceptability and Opportunity for Chlamydia Screening in Acute Care
}

\author{
Kathleen Tebb*, Mary-Ann Shafer, Fay Chang, Emily Rosenfeld, Rosanna M. Sansone and \\ Ralph Gonzales
}

University of California San Francisco, Division of Adolescent Medicine, 3333 California St, Suite 245, San Francisco, CA 94118, USA

\begin{abstract}
This study examined the acceptability of Chlamydia trachomatis screening among 138 young women in a university-based urgent care setting and the extent to which the urgent care setting represents a missed-opportunity for screening at-risk women. Most women $(86 \%)$ in need of a chlamydial test found it acceptable to be screened at their urgent care visit - even though their visit was unrelated to a reproductive health issue. Women who were in need of a chlamydial test were significantly less likely to have a primary-care provider than those who were up-to-date $(41 \% \mathrm{vs}$. $24 \%$, respectively; $X^{2}=4.2, \mathrm{df}=1, \mathrm{p}=0.04$ ). This study found chlamydial screening acceptable to young women who are being seen for non-reproductive related health visits in the urgent care setting. Implementing such efforts in urgent care settings can successfully reach a substantial proportion of at risk women who would otherwise not be screened for chlamydial.
\end{abstract}

Keywords: Chlamydia trachomatis, screening, acute care, sexually transmitted infections, young adult women.

\section{INTRODUCTION}

Chlamydia trachomatis (chlamydia) is the most common reportable sexually transmitted infection (STI) with the majority of cases among females between 15-25 years of age [1]. Chlamydia is on the rise [1-3] and remains a major cause of serious reproductive health problems in women including pelvic inflammatory disease (PID) with it's sequelae of ectopic pregnancy, chronic pelvic pain, infertility, transmission to offspring and sexual partners, and it has been linked to increased risk for HIV acquisition [1, 4-7]. Most chlamydial infections are asymptomatic [1-3]. As a result, it often goes undetected and therefore untreated. The most recent cost estimates of chlamydial infections and it's sequelae are approximately $\$ 647$ million per year (in year 2008 dollars) $[8,9]$. Chlamydial screening is one of the most effective and underutilized screening services [10-12]. Non-invasive, urine-based testing, is now widely available and has performance profiles with excellent sensitivities and specificities [13-15]. In a comparison study, the sensitivities of LCx, ProbeTec, and AC2 for chlamydia detection were 96.0, 96.0 , and $100 \%$, and the specificities were $99.1,100,98.8 \%$, respectively [14]. Once detected, chlamydia responds well to short courses of antibiotics [16]. Therefore, effective screening programs are critical to the short and long term reproductive health of women.

Annual chlamydial screening is recommended for all sexually active women aged 24 years or younger, with more frequent screening in those at greater risk [17-21]. Despite these recommendations, screening rates remain low with commercial HMO rates at $41 \%$ for $16-20$ year olds, $45 \%$ for

*Address correspondence to this author at the University of California San Francisco, Division of Adolescent Medicine, 3333 California St, Suite 245, San Francisco, CA 94118, USA; Tel: 415-514-0941; Fax: 415-476-6106; E-mail: tebbk@peds.ucsf.edu
21-24 year olds and for Medicaid 54\% for 16-20 year olds, $62 \%$ for 21-24 year olds [22]. There are a variety of barriers to chlamydial screening including system issues (e.g. insurance/payment mechanisms, clinic infrastructure, etc.) [23] and provider barriers (e.g. limited knowledge, discomfort and limited skills in taking sexual risk assessments, especially when not the primary reason for the visit) [24-26]. There are also barriers at the individual level (e.g. women do not feel at risk especially when there are no symptoms; fear of consequences of testing positive) as well as social-cultural factors [27-30]. The traditional approach to promote chlamydial screening focuses on the primary care setting. Unfortunately, many at-risk, young women do not utilize preventive health care services. Young adults are more likely to lack health insurance than any other age group [24, 31] and they do not routinely utilize preventive health services. Many young women seek same-day/acute care services when they develop a health care need. Few acute care settings routinely screen women for asymptomatic chlamydial infections. The purpose of this study was two-fold: (1) to examine young adult women's acceptability to being screened for chlamydia in an acute care setting and (2) to examine the extent to which the acute care setting represents a missed opportunity to reach women in need of a chlamydial test.

\section{MATERIALS AND METHODOLOGY}

\section{Sample and Setting}

The study was conducted over three months (between June and August 2009) on a consecutive sample of women 18-30 years of age seeking care at a university-based urgent care clinic. Although the screening recommendations are for sexually active women $15-25$ years old, women up to age 30 were included to see if there was a local need to expand screening to this population. 


\section{Exclusion Criteria}

Young women less than 18 years old were not included, as they are seen in a pediatric venue at a different location. Women with trauma or who were deemed too ill to participate by the triage nurse were excluded from participation. It should be noted that no women met this exclusion criteria during this study.

\section{Procedures}

A female medical assistant (MA) approached eligible women after triage, brought them to a private intake room, and obtained informed consent to participate. Participants completed a seven-item survey. The survey was developed by our interdisciplinary team of investigators. The MA pilot tested it with 5 women. We revised the survey based on input from the women and the MA. The survey items asked information about the reason for visit, previous sexual intercourse, time since last sexual intercourse, chlamydial tests for any reason in the past 12 months, whether or not they had a current primary care provider (PCP), and if they have had an office visit with a PCP in the past year. The MA gave all women basic information about health consequences of untreated chlamydial and chlamydial testing procedures. The MA told sexually active patients that the clinic was interested in looking at the prevalence of chlamydial and asked them if they would like to be screened at today's visit. Patients who agreed to be screened were then asked to provide $10-20 \mathrm{cc}$ of first voided urine into a sterile urine cup.

\section{Testing Methods}

All chlamydial testing was based on nucleic acid tests, and performed by the University of California San Francisco (UCSF) Microbiology Laboratory. A nurse practitioner (per clinic protocol) was notified of all positive results and was responsible for contacting patients from the confidential contact information provided at entry for scheduling a follow-up appointment for treatment, partner treatment and prevention counseling.

\section{Analyses}

Chi-square analyses compared chlamydial testing acceptability and survey items for binary variables and t-tests were used for continuous variables. Chi-square analyses were also used to examine associations between need for chlamydial test and whether or not the client had a PCP. This study was approved by the UCSF Committee on the Protection of Human Subjects.

\section{RESULTS}

A total of 138 young adult women aged 18-30 years (mean age 24.8 years) were approached during the study period and all agreed to participate. The racial/ethnic distribution was: $39 \%$ Caucasian, $21 \%$ Asian/Pacific Islander, $12 \%$ African-American, 5\% Hispanic, $1 \%$ Native American, $9 \%$ other and $13 \%$ unknown. A total of $118(86 \%)(95 \%$ $\mathrm{CI}=80,91)$ found chlamydial screening to be acceptable and agreed to provide a urine specimen for chlamydial testing at the time of their visit. Of the 20 women who declined to be tested reasons included: recently tested for chlamydia $(n=6)$; felt too ill to be tested $(n=5)$; did not have enough time $(\mathrm{n}=4)$; general feeling of being overwhelmed/feeling too stressed $(\mathrm{n}=2)$; could not urinate $(\mathrm{n}=1)$; no specified reason given $(\mathrm{n}=2)$. Table 1 provides the percent of women who found chlamydial testing acceptable by each of the survey items.

Table 1. Demographics of Participants and Acceptability of Chlamydial Testing at Acute Care Visit

\begin{tabular}{|c|c|c|}
\hline & $\begin{array}{c}\text { Accepted Test n=118 } \\
\text { N (\%) }\end{array}$ & $\begin{array}{c}\text { Declined Test n=20 } \\
\mathbf{N}(\mathbf{\%})\end{array}$ \\
\hline \hline Age & $48(82.8 \%)$ & $10(17.2 \%)$ \\
\hline $18-24$ & $70(87.5 \%)$ & $10(12.5 \%)$ \\
\hline Mean age, SD & $24.9,( \pm 2.8)$ & $24.4,2.8$ \\
\hline $\begin{array}{c}\text { No Primary care } \\
\text { provider }\end{array}$ & $44(86.3 \%)$ & $7(13.7 \%)$ \\
\hline Primary care provider & $73(84.9 \%)$ & $13(15.2 \%)$ \\
\hline Tested in last year* & $74(86.1 \%)$ & $12(14.0 \%)$ \\
\hline In need of test* & $29(78.4 \%)$ & $8(21.6 \%)$ \\
\hline Non-reproductive visit & $108(87.1 \%)$ & $16(13.1 \%)$ \\
\hline Reproductive visit & $12(85.7 \%)$ & $2(14.3 \%)$ \\
\hline $\begin{array}{c}\text { Mean days since last } \\
\text { intercourse, SD }\end{array}$ & $30.0( \pm 62.7)$ & $47.4,125.3$ \\
\hline
\end{tabular}

*Women who reported never having had sexual intercourse were excluded from these analyses.

Acceptability was not significantly associated with any of the variables assessed on the survey (e.g. race/ethnicity, age, whether or not their visit was related to a reproductive health concern; whether or not they had a primary care provider; mean days of last sexual intercourse, etc.). Women who were sexually active and who reported not having a chlamydial test in the past year were significantly more likely to also report not having a PCP than those who were up to date ( $41 \%$ vs. $24 \%$, respectively; $\left.X^{2}=4.2, \mathrm{df}=1, \mathrm{p}=0.04\right)$.

Among the 18-24 year old subgroup for which at least annual screening is recommended, 51 (88\%) reported ever having had sexual intercourse with a male partner. Of this sexually active younger group of women, $29 \%$ reported not having had a chlamydial test in the previous 12 months and of these 53\% lacked a PCP. Of the 18-24 year olds who provided a sample and were in need of screening, one tested positive $(8.3 \%)$.

\section{DISCUSSION}

This study builds on a small but growing body of research examining acute care settings as a potentially important venue to promote preventive reproductive health services such as routine chlamydial screening. This study found that the vast majority ( $86 \%$ ) of young adult women who were seeking acute care services were willing to provide a urine sample to be screened during their visit. Thirty-two percent of women in this population were in need of annual screening. Significantly more young adult women who were in need of a chlamydial test lacked a PCP than those who 
were up to date, which suggests that these women would not be screened during traditional, primary care settings.

This study is limited in that it was based on a relatively small sample size that took place in a San Francisco, university-based acute care setting where practitioners and clients are very aware of the importance for STI screening. The acceptability rate in this study is slightly higher than previously published studies which have reported acceptability rates between $(71-77 \%)$ of patients [32, 33]. Findings may not be generalizable to other populations or settings. Despite this limitation, this study provides important evidence to suggest that screening for chlamydial in acute care settings is acceptable and can take advantage of a "missed opportunity" for screening at-risk young adult women for asymptomatic chlamydial infections at a key point of contact with the health care system for this age group. In addition, the sample was representative of the larger acute care clinic population and ethnically/racially diverse in that only $39 \%$ of women came from Caucasian backgrounds. However, Hispanics are underrepresented in this clinic population and only $5 \%$ of the sample came from Hispanic backgrounds and all were English-speakers. Given the limited sample size, it was not possible to examine socio-economic and racial-ethnic differences in acceptability of chlamydial testing. More research is needed to investigate cultural, racial/ethnic and socio-economic factors that may influence young women's attitudes and how to best promote preventive screening services such as chlamydial testing among diverse populations.

\section{CONCLUSION}

Many young adults rely on acute care settings for their health care needs, placing an added burden on an already constrained health care setting. With rising unemployment rates and gaps in health coverage for this age group, they will increasingly rely on acute care for their primary contact with the medical system. Until this larger systemic issue is addressed, we need to interface with young adults where they are frequently seen for care - regardless of the setting or visit type in order to address this epidemic and identify strategies that can promote the delivery of such essential preventive services. Future research designed to promote chlamydial screening needs to focus on the development and evaluation of innovative cost-effective health delivery paradigms that address the unique needs and risks of this young population while minimizing the impact on overburdened providers and clinic staff - especially those in acute care settings. It should be noted that while it is important to offer chlamydial screening in acute care settings, providing this service is not a substitute for a comprehensive reproductive health risk assessment. Programs that provide chlamydial screening in acute care settings should emphasize to young women the importance of a reproductive health visit with a PCP and promote those linkages whenever possible.

\section{SOURCES OF SUPPORT}

This study was supported by grant R40MC08719 from the Maternal and Child Health Bureau/Health Resources and Services Administration. Dr. Shafer was also supported in part by a Leadership in Adolescent Health interdisciplinary training grant MC00003 from the Maternal and Child Health Bureau.

\section{REFERENCES}

[1] Centers for disease control and prevention. Sexually transmitted disease surveillance, 2009. Atlanta, GA: Centers for disease prevention. Division of STD prevention national center for HIV, STD and TB Prevention 2010.

[2] Annual CDC report finds high burden of sexually transmitted diseases, especially among women and racial minorities. Centers for disease control and prevention, national center for HIV/AIDS, viral hepatitis, STD, and TB prevention [Press Release]. January 13, 2009. Available at: http://www.cdc.gov/ nchhstp/newsroom/ PressRelease 011309.html

[3] Centers for disease control and prevention. Sexually transmitted disease surveillance 2007 supplement, chlamydia prevalence monitoring project annual report 2007. Atlanta, GA: US department of health and human services, centers for disease control and prevention; January 2009.

[4] Centers for disease control and prevention. STD Prevention: Some Facts About Chlamydia. Atlanta, GA: Centers for Disease Control and Prevention, Division of Sexually Transmitted Diseases, National Center for HIV, STD and TB Prevention 2001

[5] Cates W, Jr. Chlamydial infections and the risk of ectopic pregnancy. JAMA 1999; 281(2): 117-8.

[6] Shafer MA, Sweet RL. Pelvic inflammatory disease in adolescent females. Epidemiology, pathogenesis, diagnosis, treatment, and sequelae. Pediatr Clin North Am 1989; 36(3): 513-32.

[7] Ness RB, Smith KJ, Chang CC, Schisterman EF, Bass DC. Prediction of pelvic inflammatory disease among young, single, sexually active women. Sex Transm Dis 2006; 33(3): 137-42.

[8] Chesson HW, Blandford JM, Gift TL, Tao G, Irwin KL. The estimated direct medical cost of sexually transmitted diseases among American youth, 2000. Perspect Sex Reprod Health 2004; 36(1): 11-9.

[9] Weinstock H, Berman S, Cates W, Jr. Sexually transmitted diseases among American youth: incidence and prevalence estimates, 2000. Perspect Sex Reprod Health 2004; 36(1): 6-10.

[10] $\mathrm{Hu} \mathrm{D}$, Hook EW, 3rd, Goldie SJ. Screening for Chlamydia trachomatis in women 15 to 29 years of age: a cost-effectiveness analysis. Ann Intern Med 2004; 141(7): 501-13.

[11] Welte R, Kretzschmar M, Leidl R, van den Hoek A, Jager JC, Postma MJ. Cost-effectiveness of screening programs for Chlamydia trachomatis: a population-based dynamic approach. Sex Transm Dis 2000; 27(9): 518-29.

[12] Hillis SD, Nakashima A, Amsterdam L, et al. The impact of a comprehensive chlamydia prevention program in Wisconsin. Fam Plann Perspect 1995; 27(3): 108-11.

[13] Shafer MA, Moncada J, Boyer CB, Betsinger K, Flinn SD, Schachter J. Comparing first-void urine specimens, self-collected vaginal swabs, and endocervical specimens to detect Chlamydia trachomatis and Neisseria gonorrhoeae by a nucleic acid amplification test. J Clin Microbiol 2003; 41(9): 4395-9.

[14] Gaydos CA, Theodore M, Dalesio N, Wood BJ, Quinn TC. Comparison of three nucleic acid amplification tests for detection of Chlamydia trachomatis in urine specimens. J Clin Microbiol 2004; 42(7): 3041-5.

[15] Laboratory diagnostic testing for Chlamydia trachomatis and Neisseria gonorrhoeae: Expert consultation meeting summary report. Atlanta, GA: Association of Public Health Laboratories; 2009.

[16] Centers for disease control and prevention. Sexually Transmitted Disease Treatment Guidelines, 2010. MMWR 2010; 59(No. RR12): 1-109.

[17] Elster A, Kuznets N. AMA Guidelines for Adolescent Preventive Services (GAPS): recommendations and rationale. Baltimore: Williams \& Wilkins 1994

[18] Hagan JF, Shaw JS, Duncan PM, Eds. Bright futures: guidelines for health supervision of infants, children, and adolescents. $3^{\text {rd }}$ ed. Elk Grove Village, IL: American Academy of Pediatrics 2008.

[19] Burstein G, Jacobs A, Kissin D, Workowski K. Changes in the 2010 STD Treatment Guidelines: What adolescent health care providers should know. American congress of obstetricians and gynecologists. [Retrieved 2011 March 11]. Available from: 
http://www.acog.org/departments/dept_notice.cfm?recno=7\&bullet in $=5545$

[20] Healthy people 2020: Sexually transmitted diseases objectives. US Department of Health and Human Services. [Retrieved 2011 Mar 15] Available from: http://www.healthypeople.gov/2020/ topicsobjectives2020/pdfs/STDs.pdf

[21] Screening for chlamydial infection: U.S. Preventive Services Task Force recommendation statement. Ann Intern Med 2007; 147(2): 128-34.

[22] National committee for quality assurance. The state of health care quality: 2010. Washington, DC: National committee for quality assurance; 2010.

[23] Shafer MA, Tebb KP, Pantell RH, et al. Effect of a clinical practice improvement intervention on Chlamydial screening among adolescent girls. JAMA 2002; 288(22): 2846-52.

[24] Brindis C, Mulye TP, Park MJ, Irwin CE. Young people's health care: A national imperative: National Institute for health care management research and education foundation 2006.

[25] Cook RL, Wiesenfeld HC, Ashton MR, Krohn MA, Zamborsky T, Scholle SH. Barriers to screening sexually active adolescent women for chlamydia: a survey of primary care physicians. J Adolesc Health 2001; 28(3): 204-10.

[26] Guerry SL, Bauer HM, Packel L, et al. Chlamydia screening and management practices of primary care physicians and nurse practitioners in California. J Gen Intern Med 2005; 20(12): 110207.
[27] Chacko MR, von Sternberg K, Velasquez MM, Wiemann CM, Smith PB, DiClemente R. Young women's perspective of the pros and cons to seeking screening for chlamydia and gonorrhea: an exploratory study. J Pediatr Adolesc Gynecol 2008; 21(4): 187-93.

[28] Parrish DD, Kent CK. Access to care issues for African American communities: implications for STD disparities. Sex Transm Dis 2008; 35(12 Suppl): S19-22.

[29] Blake DR, Kearney MH, Oakes JM, Druker SK, Bibace R. Improving participation in Chlamydia screening programs: perspectives of high-risk youth. Arch Pediatr Adolesc Med 2003; 157(6): 523-9.

[30] Banikarim C, Chacko MR, Wiemann CM, Smith PB. Gonorrhea and chlamydia screening among young women: stage of change, decisional balance, and self-efficacy. J Adolesc Health 2003; 32(4): 288-95.

[31] Collins SR, Schoen C, Kriss JL, Doty MM, Mahato B. Rite of passage? Why young adults become uninsured and how new policies can help. Issue Brief (Commonw Fund) 2006; 20: 1-14.

[32] Aldeen T, Haghdoost A, Hay P. Urine based screening for asymptomatic/undiagnosed genital chlamydial infection in young people visiting the accident and emergency department is feasible, acceptable, and can be epidemiologically helpful. Sex Transm Infect 2003; 79(3): 229-33.

[33] Monroe KW, Weiss HL, Jones M, Hook EW, 3rd. Acceptability of urine screening for Neisseria gonorrheae and Chlamydia trachomatis in adolescents at an urban emergency department. Sex Transm Dis 2003; 30(11): 850-3.

(C) Tebb et al.; Licensee Bentham Open.

This is an open access article licensed under the terms of the Creative Commons Attribution Non-Commercial License (http://creativecommons.org/licenses/by$\mathrm{nc} / 3.0 /$ ), which permits unrestricted, non-commercial use, distribution and reproduction in any medium, provided the work is properly cited. 